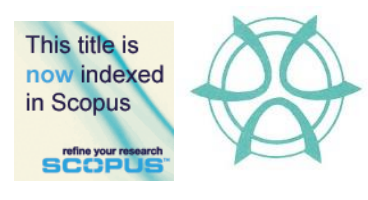

PLANNING MALAYSIA:

Journal of the Malaysian Institute of Planners

VOLUME 16 ISSUE 2 (2018), Page 275 - 284

\title{
ASSESSMENT ON SITTING POSTURE RELATION TO RISK FACTORS BY USING CHI-SQUARE TEST AMONG ELDERLY TAXI DRIVERS IN PENINSULAR MALAYSIA
}

\author{
Ahmad Zuhairi Abdul Majid ${ }^{1}$, Irwan Syah Md Yusoff ${ }^{2} \&$ Shamsul Bahri \\ Mohd Tamrin ${ }^{3}$ \\ ${ }^{1,2}$ School of Arts \\ UNIVERSITI SAINS MALAYSIA \\ ${ }^{3}$ Faculty of Medicine and Health Science \\ UNIVERSITI PUTRA MALAYSIA
}

\begin{abstract}
There are numerous factors to take into account to ensure the elderly taxi drivers perform well at work while maintaining a good health. This paper is aimed to assess sitting posture of elderly taxi drivers in Peninsular Malaysia using chisquare test. A cross-sectional study was conducted with elderly taxi drivers using a self-administered questionnaire. The survey results deliver details of sociodemographic, work characteristics and sitting comfort of older taxi drivers. Purposive sampling was used targeting at 60 years old and older, self-driving taxi for at least 1 year, no disabilities and registered with Land Public Transport Commission (LPTC). A total of 120 respondents participated in the study. Most of the respondents used 'hired' car (76.7\%). More than half of respondents had back pain in the past 12 months and $67.5 \%$ felt back pain in the last seven days. There are significant relationships $(p<0.05)$ between discomfort due to seat design and (i) BMI, (ii) smoking status, (iii) driving until midnight, (iv) feeling back pain for the last 12 months and last seven days. The lower body parts are susceptible to musculoskeletal disorders (MSDs) symptom and low back pain (LBP) injuries. Inappropriate sitting posture may cause discomfort and lead to MSDs. The lack of awareness on ergonomics design for sitting comfort lead to poor lifestyle and health issues among elderly taxi drivers in Malaysia.
\end{abstract}

Keyword: chi square, elderly, taxi driver, seating posture, ergonomics 
Ahmad Zuhairi Abdul Majid, Irwan Syah Md Yusoff \& Shamsul Bahri Mohd Tamrin

Assessment on Sitting Posture Relation to Risk Factors by Using Chi-Square Test Among Elderly Taxi Drivers in Peninsular Malaysia

\section{INTRODUCTION}

Malaysia's population in the year 2000 was approximately 23.3 million and the number grew each year. It is expected that the aging community to serve their even though after pension as they have acclimated with their previous working environment. Department of Social Welfare Malaysia (DSWM) described people who aged 60 years old and above fall into a category of elderly as referred to "World Assembly On Ageing 1982" in Vienna. Past research indicated that approximately one-third of pensioners are vulnerable to poor retirement and outcomes in term of life satisfactions and well-being (Solinge \& Henkens, 2008; Wang, 2007). Therefore, the elderly community tend to find other jobs after pension according to their health and ability. In other case, they tend to work part time jobs to financially support their family or to sustain life in the financially challenging world. It is found that the elderly community prefer to work as taxi drivers after retirement. Driving taxi is considered as manageable job that requires less energy, low cost, no specific requirement (standard licensed) and no specific regulation. It is also an advantage if they have experience in driving on commercial or private car.

Numerous factors should be considered to ensure the elderly taxi drivers could perform well at work and insure their life with good health and safety. The first factor is time. Taxi drivers spend a longer time in driving than other professions (Raanaas \& Anderson, 2008; Figà-Talamanca et al., 1996; Dalziel \& Job, 1997). The second factor is the practices of lugging of too much baggage weight and sleeping on the car seat during rest breaks (Raanaas \& Anderson, 2008). Several occupational factors such as whole-body vibration, long working hours, cramped driving space, shocks due to road surface, total mileage, time employed as a taxi driver, job dissatisfaction and job stress have been found to be important determinants of back pain among taxi drivers (Bovenzi \& Zadini, 1992; Chen, Chang, Chang, \& Christiani, 2005; Funakoshi, Taoda, Tsujimura, \& Nishiyama, 2004). Taxi drivers spend long working hours at road per-day. Excessive driving distance and working hours lead to negative impacts to the elderly taxi drivers. Most of the elderly taxi drivers' physical and mental health are poor. The average working time for taxi drivers are 10.5 hours per day for 6.4 days per week (Yang et al., 2014). Most taxi drivers suffer from the work-related diseases. Taxi drivers have a high risk of disrupting their biological clock and are at risk of body injuries; low back pain, neck disorder, carpal tunnel syndrome, depression, tension, fatigue, insomnia and other diseases (Yang et al., 2014). Other occupational factors such as whole-body vibration, long working hours, cramped driving space, shocks due to road surface, total mileage, job dissatisfaction and job stress have been found to be important determinants of low-back pain among taxi drivers (Bovenzi \& Zadini, 1992; Chen et al., 2005; Funakoshi et al., 2004). These occupational factors speed the aging process of taxi drivers and exposed them to more injuries. 
PLANNING MALAYSIA

Journal of the Malaysia Institute of Planners (2018)

Ergonomics is one of the significant factors to be considered in designing a seat. Drivers' seats such as seat pans, seat inclination, sitting without lumber support and awkward body posture bending during driving were reported in MSDs as causes of lower back pain. According to Kroemer (2017), ergonomics is the application of scientific principles, methods, and data drawn from a variety of disciplines to the development of engineering systems in which people play a significant role. One of the most important contributions that ergonomics can provide to the automobile design process is information of the physical size of driver, and his/her preferred postures (Hirao, Kitazaki, \& Yamazaki, 2006). The current awareness on comfort and discomfort is lacking, while the need for this knowledge is crucial since people use products related to comfort everyday (Vink \& Hallback, 2012). Many authors have yet to find any study that directly assess the association between awareness of Ergonomics factors and MSD on sitting posture among elderly taxi drivers in Peninsular Malaysia. This paper aims to assess the sitting posture relating to risk factors among elderly taxi drivers in Peninsular Malaysia by using chi-square test.

\section{METHODS}

The study employed cross-sectional survey using questionnaires to investigate characteristics of driving background and prevalence of discomfort on sitting posture among elderly taxi drivers in Peninsular Malaysia. The study was conducted at rural and urban areas in four regions of peninsular Malaysia. A purposive sampling was chosen and 120 respondents participated in the study. Sampling criteria include (i) age above 60 years old, (ii) have at least 1 year taxi driving experience, (iii) registered with LPTC, (iv) have no history of major surgery or history of neurological problems. Taxi drivers that attended any courses or training on occupational health and were part-time taxi drivers of less than 4 hours driving per-day were excluded. Types of taxi services involved are the 'budget car' and 'hired' car. Respondents in peninsular Malaysia aging 60 years above driving 'budget car' and 'hired' car with standard seat design. No modification on the seat is involved. Each survey took approximately 10 to 15 minutes to complete. Participants were asked kindly if they agree to take part. A complete survey form would include work characteristics, some health issues of taxi drivers and sitting posture details.

A self-administered questionnaire was distributed to the participants. The interview was conducted face to face with elderly taxi drivers to obtain good result and minimize miss-interpreted responses. The questions were divided into three sections. The first part of the questionnaire is on socio-demographic factors. The second part of the questions are on characteristics and the third part include questions on the body part discomfort map from each body part on the sitting driving position. The questions were adapted from the United States driving ergonomics program. A body discomfort map diagram was used and the diagram 
Ahmad Zuhairi Abdul Majid, Irwan Syah Md Yusoff \& Shamsul Bahri Mohd Tamrin

Assessment on Sitting Posture Relation to Risk Factors by Using Chi-Square Test Among Elderly Taxi Drivers in Peninsular

Malaysia

assist the elderly taxi drivers in identifying the correct body parts in answering the questions as shown in Figure 1.

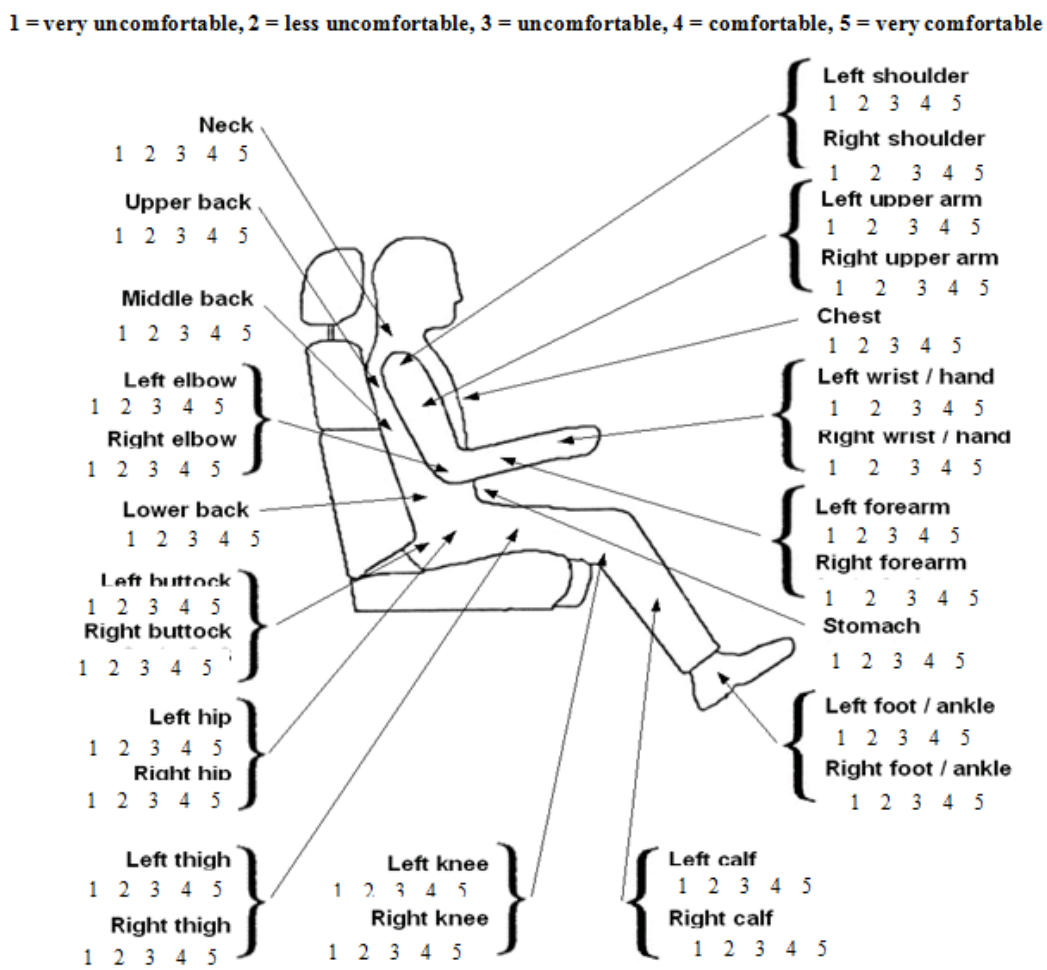

Figure 1: Discomfort body parts maps Source: Adopted from United States driving ergonomics program

The interview was conducted in parking spaces of bus station, train station, shopping malls and taxi stand areas in Serdang city and Putrajaya. All selected taxi were chosen in this study were registered with SPAD under taxi services that cover the budget and hired car. Besides that, these taxi types were classified as economy taxi and the car seat design underlined in standard/normal specification compared to other taxi services. The analysis was performed using SPSS software version 20. Descriptive statistics were obtained for all the variables in the study.

\section{RESULTS}

The majority of elderly drivers used 'hired car' as a type of taxi $(76.7 \%$. All respondents were male. Mean $( \pm \mathrm{SD})$ age of the respondents was $64.7 \pm 4.0$ and the age ranged from 60 to 77 years old. Most of elderly taxi drivers aged between 60 
PLANNING MALAYSIA

Journal of the Malaysia Institute of Planners (2018)

to 65 years old $(60 \%)$. The majority of the respondents were Malay $(78.3 \%)$ followed by Indian (13.3\%). The majority of respondents were self-employed $(56.7 \%)$. The smoking status were relatively equal between frequent smokers (55.0\%) and non-smokers (45.0\%) as shown in Table 1.

Tables 1: Background of elderly taxi drivers.

\begin{tabular}{lcccc}
\hline Factors & $\mathbf{N}(\%)$ & Mean $\pm($ S.D $)$ & Min & Max \\
\hline Category taxi & $92(76.7)$ & & & \\
Hired car & $28(23.3)$ & & & \\
Budget & $72(60)$ & & & \\
Age & $48(40)$ & & \\
$60>65$ & $94(78.3)$ & & \\
$>66$ & $16(13.3)$ & & \\
Ethnicity & $10(8.3)$ & & \\
Malay & & & \\
India & $52(43.3)$ & & \\
Chinese & $68(56.7)$ & & \\
Jobs sectors & & & \\
Company & & & \\
Self - employed & $66(55.0)$ & & \\
Smoking status & $54(45.0)$ & & \\
Yes/frequent & & & \\
No/never & & & \\
\hline N=120 & & & \\
\hline
\end{tabular}

Table 2 shows that $75.8 \%$ of the respondents exceeded $250 \mathrm{~km}$ driving distance per week. Less than half of the respondents (45.8\%) never drove their taxi until midnight while $15.8 \%$ of the respondents tend to drive until midnight. $76.7 \%$ of the respondents complained having back pain in the last 12 months and $67.5 \%$ of the respondents reported feeling back pain in the past 7 days. The taxi drivers agreed that the back pain were caused by their work environment (89.2\%). Most of them tend to carry passengers' luggage into the trunks (95.0\%). 44.2\% of the respondents claimed to have experienced driving taxi for 16 years and more.

Table 2: Characteristics of elderly taxi driver

\begin{tabular}{lr}
\hline Factors & $\mathbf{N}(\%)$ \\
\hline Average distance driving per-week & \\
$51>150 \mathrm{~km}$ & $4(7.5)$ \\
$151>250 \mathrm{~km}$ & $25(20.0)$ \\
$>250 \mathrm{~km}$ & $91(75.8)$ \\
Driving until mid-night &
\end{tabular}


Ahmad Zuhairi Abdul Majid, Irwan Syah Md Yusoff \& Shamsul Bahri Mohd Tamrin

Assessment on Sitting Posture Relation to Risk Factors by Using Chi-Square Test Among Elderly Taxi Drivers in Peninsular Malaysia

\begin{tabular}{lr} 
Always & $19(15.8)$ \\
Not frequent & $46(38.3)$ \\
Never & $55(45.8)$ \\
Past 12 month feeling back pain & \\
Yes & $92(76.7)$ \\
No & $28(23.3)$ \\
Past 7 days feeling back pain & \\
Yes & $81(67.5)$ \\
No & $39(32.5)$ \\
Feeling back pain cause of job & \\
Yes & $107(89.2)$ \\
No & $13(10.8)$ \\
Carry luggage into trunk & \\
Yes & $114(95.0)$ \\
No & $6(5.0)$ \\
Total driving experience & \\
$1>5$ yrs & $32(26.7)$ \\
$6>15 y r s$ & $35(29.2)$ \\
$>16 y r s$ & $53(44.2)$ \\
\hline
\end{tabular}

The results from Table 3 show that most of the taxi drivers complaint that the highest body part were very uncomfortable. Discomfort body parts include lower back (63.3\%), right buttock (62.5\%), and left buttock (61.7\%). 33.3\% of the respondents claimed to experience small discomfort at upper back and center back $(32.5 \%)$, right thigh $(30.8 \%)$ and neck $(18.3 \%)$. Overall, the majority of the respondents $(92.5 \%)$ agreed that the discomfort of body parts were caused by car seat design.

Table 3: Discomfort body map of elderly taxi drivers

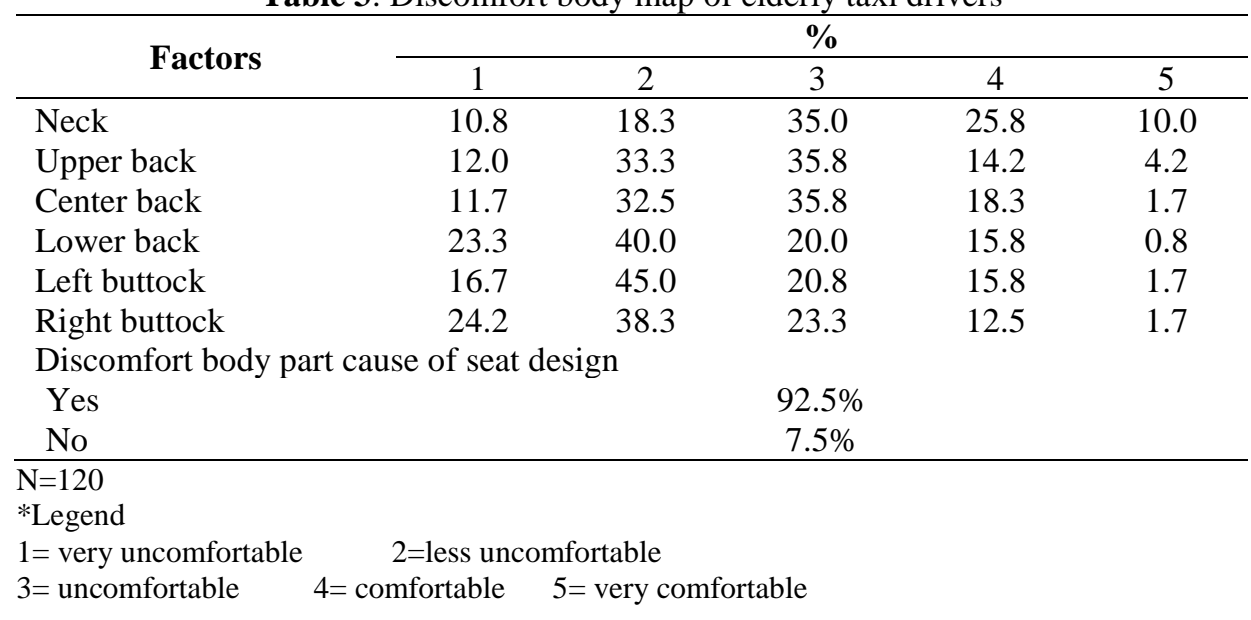


PLANNING MALAYSIA

Journal of the Malaysia Institute of Planners (2018)

Table 4 indicates that (i) the discomfort body parts due to seat design, (ii) risk factors, (iii) socio-demographic factors had significant relationship with BMI $25 \geq 40\left(\mathrm{X}^{2}: 4.31, p: 0.03\right)$ and smoking status $\left(\mathrm{X}^{2}=4.22, p=0.04\right)$. Others variables like age, education level and job sectors had no significant relationship with the discomfort body parts due to seat design. Additionally, characteristics of elderly taxi drivers had significant relationship with 'always driving until midnight' $\left(\mathrm{X}^{2}: 5.97, p\right.$ : 0.01$)$, feeling back pain in past 12 month $\left(\mathrm{X}^{2}: 5.64, p\right.$ : $0.01)$, feeling back pain in the past 7 days $\left(X^{2}: 14.10, p: 0.00\right)$, feeling back pain due to the job $\left(\mathrm{X}^{2}: 5.10, p: 0.02\right)$ and feeling back pain due to carrying luggage into the trunks $\left(\mathrm{X}^{2}: 16.44, p: 0.00\right)$. On the other hand, average hours driving per week, average distance driving per week and total driving experience did not contribute to discomfort body posture.

Table 4: Risk factors with discomfort body posture on seat design (Chi Square test)

\begin{tabular}{|c|c|c|c|c|}
\hline \multirow[t]{2}{*}{ Variables } & \multicolumn{2}{|c|}{$\begin{array}{c}\text { Discomfort body posture } \\
\text { on seat design }\end{array}$} & \multirow[t]{2}{*}{$\begin{array}{c}\text { Chi Square } \\
\text { value }\left(\mathbf{X}^{2}\right)\end{array}$} & \multirow[t]{2}{*}{$P$ value } \\
\hline & Yes & No & & \\
\hline \multicolumn{3}{|l|}{ BMI } & 4.31 & $0.03 * *$ \\
\hline$\leq 15 \geq 25$ & 43.3 & 0.8 & & \\
\hline $25 \geq 40$ & 49.2 & 6.7 & & \\
\hline \multicolumn{3}{|l|}{ Education level } & 0.11 & 0.73 \\
\hline Primary \& none & 35.8 & 3.3 & & \\
\hline Secondary \& highest & 56.7 & 4.2 & & \\
\hline \multicolumn{3}{|l|}{ Jobs sectors } & 0.59 & 0.44 \\
\hline Company & 39.2 & 4.2 & & \\
\hline Self - employed & 53.3 & 3.3 & & \\
\hline \multicolumn{3}{|l|}{ Smoking status } & 4.22 & $0.04 * *$ \\
\hline Yes/frequent & 53.3 & 1.7 & & \\
\hline No/never & 39.2 & 5.8 & & \\
\hline \multicolumn{3}{|c|}{ Average distance driving per-week } & 1.82 & 0.17 \\
\hline$\leq 150 \mathrm{~km}$ & 2.5 & 0.8 & & \\
\hline$\geq 151 \mathrm{~km}$ & 90.0 & 6.7 & & \\
\hline \multicolumn{3}{|c|}{ Driving until mid-night } & 5.97 & $0.01 * *$ \\
\hline Not frequent \& never & 80.0 & 4.2 & & \\
\hline Always & 12.5 & 3.3 & & \\
\hline \multicolumn{3}{|c|}{ Past 12 month feeling back pain } & 5.64 & $0.01 * *$ \\
\hline No & 19.2 & 4.2 & & \\
\hline Yes & 73.3 & 3.3 & & \\
\hline \multicolumn{3}{|c|}{ Past 7 days feeling back pain } & 14.10 & $0.00 * *$ \\
\hline No & 25.8 & 6.7 & & \\
\hline & 66.7 & 0.8 & & \\
\hline \multicolumn{3}{|c|}{ Feeling back pain cause of job } & 5.10 & $0.02 * *$ \\
\hline No & 8.3 & 2.5 & & \\
\hline Yes & 84.2 & 5.0 & & \\
\hline \multicolumn{3}{|c|}{ Carry luggage into boot } & 16.44 & $0.00 * *$ \\
\hline
\end{tabular}


Ahmad Zuhairi Abdul Majid, Irwan Syah Md Yusoff \& Shamsul Bahri Mohd Tamrin

Assessment on Sitting Posture Relation to Risk Factors by Using Chi-Square Test Among Elderly Taxi Drivers in Peninsular

Malaysia

\begin{tabular}{lcccc} 
No & 2.5 & 2.5 & & \\
Yes & 90.0 & 5.0 & & \\
Total driving experience & & & 0.22 & 0.63 \\
$\quad<5$ years & 24.2 & 2.5 & & \\
$>5$ years \& above & 68.3 & 5.0 & & \\
\hline $\mathrm{N}=120$ & & &
\end{tabular}

\section{DISCUSSION}

In this study, more than half of the respondents age ranged between 60 to 65 years old. Previous study conducted by Welch, Haile, Boden and Hunting (2009) indicated that low back pain occurs between 30 and 50 years old and cost approximately $30 \%$ of expenditure due to soft tissue damaged. According to Pruesser, Williams, Ferguson, Ulmer and Weinstein (1998), taxi drivers that were between 65 and 69 years old were 2.26 times higher at risk of fatal multi-vehicle crash compared to taxi drivers that were between 40 and 49 years old.

In Nigeria, $85 \%$ of taxi drivers were engaged in driving business as means of living (Onawumi \& Lucas, 2012). The findings showed that almost the same percentage of taxi drivers (85\%) were either working full time or selfemployed to financially sustain their life and their family.

In addition, the findings revealed that there were significant relationship between discomfort body parts due to seat design and (i) smoking status and (ii) BMI (obese). The result were similar with those reported previously (Al-Dubai, Qureshi, Ismail, \& Rampal 2012). The findings were also consistent with another research (Miyamoto et al., 2008) that driving long hours and driving late at night had significant relationships with discomfort body parts due to seat design. The longer time spent daily or weekly to pick up and waiting for passengers lead to back injury (Miyamoto et al., 2008).

$76.7 \%$ and $67.5 \%$ of the respondents claimed to experienced back pain in the past 12 months and in the past seven days respectively. Based on the discomfort body parts map, the highest complaints of discomfort were on back body parts compared to other body parts. Previous research (Chen et al., 2005; Funakoshi et al., 2004) revealed similar findings that prevalence of lower back parts among taxi drivers were $45.8 \%$ in Japan and 51\% in Taiwan.

The findings of the study indicated that long years of working experience were related to sitting discomfort. Elderly drivers that have 6 years to 15 years driving experiences tend to face discomfort body parts. The previous survey study conducted with professional drivers found a significant association between low back parts and duration of employment as a bus driver (Tamrin et al., 2007). However, some studies on taxi drivers did not find such relationship. Instead, the studies indicated that there was no relationship between years of experiences as taxi drivers and discomfort body parts (Chen et al., 2005). 
The study found that years of carrying passengers' luggage into the trunks led to discomfort of body parts. Most of taxi drivers suffer from workrelated diseases. The work tend to disrupt their biological clock and often lead to body injuries such as low back pain, neck disorder, carpal tunnel syndrome, depression, tension, fatigue, insomnia and other diseases (Yang et al., 2014).

\section{CONCLUSION}

In general, this study deliver the perspectives of elderly taxi drivers on sitting posture. The study identified the risk factors of sitting posture that would lead to injury or pain due to seat design. The findings were helpful in initiating the prevention of MSDs or developing body parts injuries through determining which body part may develop the cumulative injuries. The limitation of the study is the insufficient sample size to represent the population of elderly taxi driver in Peninsular Malaysia. Ergonomics intervention approach would reduce MSD related problems. In an attempt to improve the safety and wellbeing of the elderly community, future studies on the topic is highly encouraged.

\section{ACKNOWLEDGEMENT}

We would like to thank to the Malaysian Consumer and Family Economics Association (MACFEA) for providing funds under the Mini Grants MACFEA 2017 scheme to conduct this study. We are also thankful to Universiti Sains Malaysia for the journal publication fund. The contents of this paper are solely the responsibility of the authors and do not necessarily represent the official views of the sponsors.

\section{REFERENCES}

Al-Dubai, S. A. R., Qureshi, A. M., Ismail, N. H., \& Rampal, K. G. (2012). Prevalence and determinants of low back pain among taxi drivers in Malaysia. A cross sectional study. Journal of Advanced Medical Research, 2(4), 129-43.

Bovenzi, M., \& Zadini, A. (1992). Self-reported low back symptoms in urban bus drivers exposed to whole-body vibration. Spine, 17(9), 1048-1059.

Chen, J. C., Chang, W. R., Chang, W., \& Christiani, D. (2005). Occupational factors associated with low back pain in urban taxi drivers. Occupational Medicine, 55(7), 535-540.

Dalziel, J. R., \& Job, R. S. (1997). Motor vehicle accidents, fatigue and optimism bias in taxi drivers. Accident Analysis \& Prevention, 29(4), 489-494.

Figà-Talamanca, I., Cini, C., Varricchio, G. C., Dondero, F., Gandini, L., Lenzi, A. \& Patacchioli, F. R. (1996). Effects of prolonged autovehicle driving on male reproductive function: a study among taxi drivers. American Journal of Industrial Medicine, 30(6), 750-758.

Funakoshi, M., Taoda, K., Tsujimura, H., \& Nishiyama, K. (2004). Measurement of 
Ahmad Zuhairi Abdul Majid, Irwan Syah Md Yusoff \& Shamsul Bahri Mohd Tamrin

Assessment on Sitting Posture Relation to Risk Factors by Using Chi-Square Test Among Elderly Taxi Drivers in Peninsular Malaysia

whole-body vibration in taxi drivers. Journal of occupational health, 46(2), 119124.

Hirao, A., Kitazaki, S., \& Yamazaki, N. (2006). Development of a new driving posture focused on biomechanical loads (No. 2006-01-1302). SAE Technical Paper.

Kroemer, K. H. (2017). Fitting the human: Introduction to ergonomics/human factors engineering. Boca Raton: CRC Press.

Miyamoto, M., Konno, S., Gembun, Y., Liu, X., Minami, K., \& Ito, H. (2008) Epidemiological study of low back pain and occupational risk factors among taxi drivers. Industrial Health, 46(2), 112-117.

Onawumi, A. S., \& Lucas, E. B. (2012). Ergonomic Investigation of Occupational Drivers and Seat Design of Taxicabs in Nigeria. ARPN Journal of Science and Technology, 2(3), 214-220.

Preusser, D. F., Williams, A. F., Ferguson, S. A., Ulmer, R. G., \& Weinstein, H. B. (1998) Fatal crash risk for older drivers at intersections. Accident Analysis \& Prevention, 30(2), 151-159.

Raanaas, R. K., \& Anderson, D. (2008). A questionnaire survey of Norwegian taxi drivers' musculoskeletal health, and work-related risk factors. International Journal of Industrial Ergonomics, 38(3), 280-290.

Solinge, H., \& Henkens, K. (2008). Adjustment to and satisfaction with retirement: Two of a kind? Psychology and Aging, 23,422-434.

Tamrin, S. B. M., Yokoyama, K., Jalaludin, J., Aziz, N. A., Jemoin, N., Nordin, R., ... \& Abdullah, M. (2007). The association between risk factors and low back pain among commercial vehicle drivers in peninsular Malaysia: a preliminary result. Industrial Health, 45(2), 268-278.

Vink, P., \& Hallbeck, S. (2012). Editorial: Comfort and discomfort studies demonstrate the need for a new model. Applied ergonomics, 43(2), 271-276.

Wang, M. (2007). Profiling retirees in the retirement transition and adjustment process: examining the longitudinal change patterns of retirees' psychological wellbeing. Journal of Applied Psychology, 92(2), 455.

Welch, L., Haile, E., Boden, L. I., \& Hunting, K. L. (2009). Musculoskeletal disorders among construction roofers - physical function and disability. Scandinavian journal of work, environment \& health, 35(1), 56-63.

Yang, Y., Fan, X. S., Tian, C. H., Zhang, W., Li, J., \& Li, S. Q. (2014). Health status, intention to seek health examination, and participation in health education among taxi drivers in Jinan, China. Iranian Red Crescent Medical Journal, 16(4), e13355. 